\title{
GMR
}

\section{Association between angiotensin-converting enzyme insertion/deletion polymorphisms and the risk of heart disease: an updated meta-analysis}

\author{
F.J. You and D.M. Shen \\ Bachelor of Medical Department, Suzhou Xiangcheng People's Hospital, Suzhou, \\ Jiangsu Province, China \\ Corresponding author: F.J. You \\ E-mail: yfengjiana@163.com \\ Genet. Mol. Res. 15 (1): gmr.15017194 \\ Received September 10, 2015 \\ Accepted November 29, 2015 \\ Published February 26, 2016 \\ DOI http://dx.doi.org/10.4238/gmr.15017194
}

ABSTRACT. Insertion/deletion (I/D) polymorphisms of the gene encoding angiotensin converting enzyme (ACE) are a controversial risk factor for heart diseases (HDs). ACE I/D polymorphism has been reported to be associated with various cardiovascular diseases. However, some studies have presented conflicting results. In this study, we aim to explore the association between ACE I/D polymorphisms and the risk of coronary HD (CHD), coronary artery disease (CAD), and myocardial infarction (MI). A meta-analysis was conducted, which included 12,533 cases and 20,726 controls from 75 case-control studies. We performed overall analysis on the entire dataset and found that the D allele of ACE was significantly associated with increased risk of HDs in three different comparison models (dominant, recessive, and homozygote). We also performed analyses on subgroups based on ethnicity as well as disease type. Our results showed that the $D$ allele of ACE was significantly associated with an increased risk of HDs in the Asian and European groups but not in the American group. In addition, in all three subgroups (CHD, CAD, and MI), the D allele of ACE 
was found to be significantly associated with increased risk of disease. Begg's funnel plots were generated to evaluate publication biases, but no obvious publication bias was found in the studies included in our metaanalysis. In conclusion, our meta-analysis demonstrated that the D allele of ACE was significantly associated with an increased risk of HDs.

Key words: Insertion/deletion polymorphism; Heart disease; Angiotensin converting enzyme; Meta-analysis

\section{INTRODUCTION}

Coronary heart disease (CHD), coronary artery disease (CAD), and myocardial infarction (MI) are different types of heart diseases (HDs), all of which are worldwide public health issues (Negi and Anand, 2010). The etiology of heart diseases involves both genetic and environmental factors, as well as their interactions (Mi et al., 2011). Racial differences in the occurrence and outcomes of heart dysfunction suggest that genetic factors play important roles in the pathogenesis of HDs (Dries et al., 1999). It has been estimated that approximately $50 \%$ of the major risk factors for HDs is determined by genetic factors (Sekuri et al., 2005). Among these genetic factors, the roles of neurohormones have been extensively studied. For example, angiotensin-converting enzyme (ACE) has been proposed to play important roles in the progression of HDs (Bautista et al., 2004; Masud and Qureshi, 2011; Chen et al., 2013).

ACE is a key enzyme in the renin-angiotensin-aldosterone system, which plays important roles in the regulation of heart function. In this system, the function of ACE is to transform angiotensin I to II, and inactivates bradykinin. In humans, ACE is a highly polymorphic gene located on chromosome 17q23, and contains 26 exons and 25 introns. An insertion/deletion (I/D) polymorphism on intron 16 of ACE, characterized by an insertion or a deletion of a 287-bp noncoding Alu repeat sequence (Rigat et al., 1992), has been demonstrated to affect ACE levels and activities (Danser et al., 1995). The DD genotype of ACE has been reported to be associated with increased risks of various HDs such as CHD/CAD and MI (Bautista et al., 2004; Pulla Reddy et al., 2010; Chen et al., 2013). However, other studies have produced inconsistent or even contradictory results (Marques-Vidal et al., 2003; Andrikopoulos et al., 2004; Zakrzewski-Jakubiak et al., 2008; Rallidis et al., 2009; Bai et al., 2012). For example, Rallidis et al. (2009) reported that ACE I/D polymorphism is not associated with early stages of MI. Similarly, Bai et al. (2012) reported that ACE I/D polymorphism is not associated with heart failures.

The lack of consistency across previous studies is due to various factors such as limited sample size and improper study designs. In our study, we aim to reconcile the inconsistencies in previous studies by carrying out a comprehensive meta-analysis on all eligible studies up to date, including 12,533 cases and 20,726 controls. We estimate the overall as well as subgroup HD risks of ACE I/D polymorphism, and quantify the between-study heterogeneity and potential biases.

\section{MATERIAL AND METHODS}

\section{Data collection}

We searched articles using Global Cross-databases including PubMed, PMC, Embase, Cochrane library, and Google Scholar, with "ACE I/D polymorphism", "angiotensin-converting 
enzyme", "coronary artery disease", "coronary heart disease", "myocardial infarction", and "heart disease" as key words. In total, 887 results were obtained. We then performed three rounds of exclusions. First, we excluded books and other articles that did not contain casecontrol studies, which reduced the number of articles to 229. Second, we excluded articles, the aim of which was not to investigate the association between ACE I/D polymorphisms and HD risks. Following this round of exclusion, 15 articles remained. Third, among these 15 articles, if studies were overlapped or duplicated, we only kept the ones showing the most extensive results. We also excluded studies in which raw data could not be retrieved. As a result, 12 articles including 75 case-control studies were used in our final meta-analysis. The data collection flow chart is shown in Figure 1.

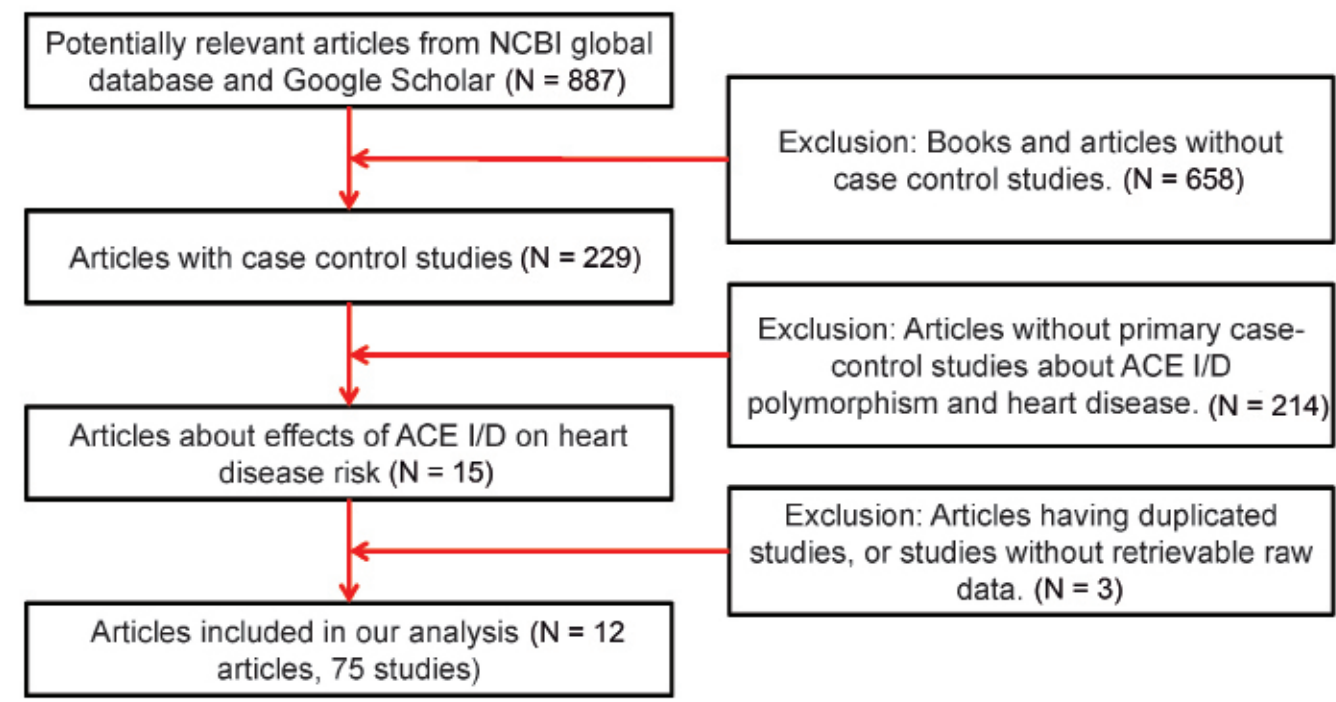

Figure 1. Data collection procedure. In total, 887 literatures were searched for the first-round exclusion. Of these, 12 literatures including 75 studies were included in the final meta-analysis.

\section{Statistical methods}

In our meta-analysis, we adopted three different models: dominant (DD + ID vs II), recessive (DD vs ID + II), and homozygote comparison (DD vs II). For the dominant model, we used II genotype as the reference group, and estimated the risk of HD in the DD + ID genotype as compared with the II genotype. For recessive model, we used ID + II genotype as the reference group, and estimated HD risk in the DD genotype as compared with the ID + II genotype. For homozygote comparison model, we used II genotype as the reference group, and estimated HD risk in the DD genotype. We presented the results as odds ratio (OR) and $95 \%$ confident interval, and considered $P<0.05$ to be statistically significant. The three models were applied to the analysis on the entire population as well as on individual subgroups. Statistical analysis was performed with the STATA 12 software (Stata Statistical Software: Release 12; StataCorp LP., College Station, TX, USA). For each study, the numbers 
of the three genotypes in case and control groups were used as pooled data. To choose the analysis model, heterogeneity was measured with $\mathrm{I}^{2}$ index, where higher $\mathrm{I}^{2}$ indicated increased heterogeneity. We considered $\mathrm{I}^{2} \leq 50 \%$ as insignificant heterogeneity within the pooled data. We then adopted the Mantel-Haenszel $(\mathrm{M}-\mathrm{H})$ fixed-effect model for datasets without significant heterogeneity, and DerSimonian and Laird (D-L) random-effect model for datasets with significant heterogeneity. For each analysis, we used $\mathrm{M}-\mathrm{H}$ fixed-effect model to test heterogeneity first, and then chose the proper model based results from the heterogeneity tests. ORs were calculated for each model with 95\% confidence intervals. Forest plots were generated to summarize the results. To evaluate potential publication bias, Begg's funnel plots were generated based on the results and database size, where increased asymmetry in the funnel plots indicated increased publication biases.

\section{RESULTS}

\section{Characteristics of eligible studies}

To evaluate the association between ACE I/D polymorphism and risk of heart diseases, we performed a meta-analysis based on 75 studies in which the association between ACE I/D polymorphism and human heart disease risk was examined (Yang, 2000; Dai, 2003; Ai, 2005; Araújo et al., 2005; Zhang, 2003, 2004, 2006; Li, 2004, 2008; Yu et al., 2009; Dhar et al., 2010; Wang, 2009, 2010; Zhu, 2010; Pandey et al., 2011; Yi, 2011; Firouzabadi et al., 2012; Dai et al., 2013; Fang et al., 2014; Moradzadegan et al., 2014). After pooling all data, our meta-analysis contained 12,533 cases and 20,726 controls. The characteristics of all 75 studies are shown in Table 1.

\section{ACE I/D polymorphisms and HD risk}

To conduct risk assessment on all case and control patients, we started with the $\mathrm{M}-\mathrm{H}$ fixed-effect model to determine heterogeneity in three different comparison models (dominant, recessive, and homozygote). The values of $\mathrm{I}^{2}$ for dominant, recessive, and homozygote models were $70.6,68.3$, and $67.7 \%$, respectively, which indicated that there was significant heterogeneity (Table 2). Therefore, we used a D-L random-effect model for further analyses in all three models. For the dominant model (DD + ID vs II), the pooled OR was $2.114(95 \% \mathrm{Cl}=1.900-2.352, \mathrm{P}<$ 0.001 ), suggesting significant association between the DD + ID genotype and high HD risk (Table 2). For the recessive model (DD vs ID + II), the OR was $1.669(95 \% \mathrm{Cl}=1.495-1.864, \mathrm{P}<0.001)$, also suggesting significant association between the DD genotype and high HD risk (Table 2). For the homozygote comparison model (DD vs II), the OR was $1.877(95 \% \mathrm{Cl}=1.639-2.151, \mathrm{P}<$ 0.001 ), again suggesting significant association between the DD genotype and high HD risk (Table 2). Figure 2 illustrates the meta-analysis results for dominant (Figure 2A), recessive (Figure 2B), and homozygote models (Figure $2 \mathrm{C}$ ), respectively.

Funnel plots for all three comparison models were generated to detect the presence of publication biases (Figure 2D). The shapes of all of the funnels were generally symmetric, indicating that no obvious publication bias was introduced in the studies included in our overall meta-analysis. 
Table 1. Pooled data for ACE I/D analysis.

\begin{tabular}{|c|c|c|c|c|c|c|c|c|c|c|}
\hline \multirow[t]{2}{*}{ Study } & \multirow[t]{2}{*}{ Year } & \multicolumn{4}{|c|}{ Case } & \multicolumn{4}{|c|}{ Control } & \multirow[t]{2}{*}{ Disease } \\
\hline & & II & ID & DD & Total & II & ID & DD & Total & \\
\hline Asian & & & & & & & & & & \\
\hline Shan & 2000 & 55 & 54 & 39 & 148 & 49 & 85 & 25 & 159 & $\mathrm{CHD}$ \\
\hline$L v, b$ & 2000 & 17 & 20 & 27 & 64 & 15 & 17 & 9 & 41 & $\mathrm{MI}$ \\
\hline Tian & 2000 & 11 & 20 & 19 & 50 & 17 & 25 & 8 & 50 & MI \\
\hline Yang & 2000 & 16 & 18 & 24 & 58 & 5 & 17 & 9 & 31 & MI \\
\hline You & 2000 & 16 & 21 & 28 & 65 & 44 & 32 & 14 & 90 & MI \\
\hline Chen & 2001 & 21 & 17 & 13 & 51 & 14 & 14 & 2 & 30 & CHD \\
\hline Xie & 2001 & 32 & 55 & 19 & 106 & 37 & 36 & 13 & 86 & CAD \\
\hline Deng & 2002 & 45 & 53 & 7 & 105 & 40 & 50 & 12 & 102 & $\mathrm{CHD}$ \\
\hline Liu, b & 2002 & 7 & 26 & 18 & 51 & 22 & 48 & 13 & 83 & CHD \\
\hline $\mathrm{Su}$ & 2002 & 30 & 77 & 50 & 157 & 45 & 47 & 20 & 112 & CAD \\
\hline Dai & 2003 & 93 & 124 & 33 & 250 & 43 & 43 & 9 & 95 & $\mathrm{CHD}$ \\
\hline Huang & 2003 & 18 & 41 & 30 & 89 & 27 & 33 & 15 & 75 & CHD \\
\hline Zhang, b & 2003 & 38 & 40 & 24 & 102 & 61 & 75 & 12 & 148 & CAD \\
\hline$L i, a$ & 2004 & 17 & 59 & 53 & 129 & 36 & 39 & 15 & 90 & CAD \\
\hline Zhang, c & 2004 & 32 & 35 & 22 & 89 & 61 & 75 & 12 & 148 & CAD \\
\hline Zhu, a & 2004 & 79 & 88 & 25 & 192 & 43 & 43 & 12 & 98 & CAD \\
\hline $\mathrm{Ai}$ & 2005 & 12 & 35 & 24 & 71 & 21 & 39 & 21 & 81 & CHD \\
\hline Liang & 2006 & 40 & 55 & 38 & 133 & 71 & 59 & 24 & 154 & CAD \\
\hline Shi & 2006 & 53 & 66 & 50 & 169 & 55 & 86 & 27 & 168 & $\mathrm{CHD}$ \\
\hline Wang, a & 2006 & 37 & 44 & 24 & 105 & 22 & 24 & 4 & 50 & CAD \\
\hline Zhang, d & 2006 & 22 & 41 & 30 & 93 & 33 & 43 & 11 & 87 & $\mathrm{Ml}$ \\
\hline Qiu, b & 2007 & 39 & 41 & 50 & 130 & 30 & 47 & 13 & 90 & CHD \\
\hline $\mathrm{Li}, \mathrm{b}$ & 2008 & 10 & 40 & 30 & 80 & 13 & 50 & 37 & 100 & CAD \\
\hline Shi & 2008 & 14 & 39 & 27 & 80 & 26 & 42 & 12 & 80 & $\mathrm{CHD}$ \\
\hline Yu & 2009 & 44 & 55 & 25 & 124 & 22 & 20 & 8 & 50 & $\mathrm{CHD}$ \\
\hline Wang, b & 2009 & 64 & 49 & 37 & 150 & 63 & 66 & 21 & 150 & CAD \\
\hline Yun & 2009 & 47 & 68 & 35 & 150 & 67 & 63 & 20 & 150 & $\mathrm{CHD}$ \\
\hline Wang, c & 2010 & 48 & 49 & 64 & 161 & 33 & 49 & 27 & 109 & CAD \\
\hline Zhu, b & 2010 & 31 & 67 & 53 & 151 & 45 & 63 & 19 & 127 & CHD \\
\hline $\mathrm{Yi}_{\mathrm{i}}$ & 2011 & 76 & 59 & 45 & 180 & 72 & 83 & 25 & 180 & CHD \\
\hline Fang & 2014 & 63 & 44 & 46 & 153 & 59 & 37 & 73 & 169 & $\mathrm{CHD}$ \\
\hline Chuang & 1997 & 32 & 27 & 11 & 70 & 83 & 87 & 27 & 197 & $\mathrm{CHD}$ \\
\hline Ko & 1997 & 107 & 119 & 42 & 268 & 145 & 156 & 37 & 338 & CAD \\
\hline Lu & 1997 & 41 & 44 & 31 & 116 & 47 & 44 & 12 & 103 & $\mathrm{Ml}$ \\
\hline Tan & 1997 & 13 & 27 & 32 & 72 & 24 & 33 & 15 & 72 & $\mathrm{MI}$ \\
\hline Yuan & 1997 & 16 & 26 & 5 & 47 & 9 & 12 & 9 & 30 & $\mathrm{MI}$ \\
\hline Zhang, a & 1997 & 20 & 33 & 44 & 97 & 25 & 53 & 26 & 104 & MI \\
\hline Zheng & 1997 & 17 & 46 & 40 & 103 & 30 & 40 & 26 & 96 & $\mathrm{MI}$ \\
\hline Gu & 1998 & 25 & 37 & 33 & 95 & 43 & 44 & 13 & 100 & $\mathrm{CHD}$ \\
\hline $\mathrm{Da}$ & 1998 & 31 & 38 & 11 & 80 & 82 & 59 & 9 & 150 & $\mathrm{MI}$ \\
\hline$L v, a$ & 1998 & 16 & 18 & 24 & 58 & 15 & 17 & 9 & 41 & MI \\
\hline Lai, b & 1999 & 13 & 24 & 26 & 63 & 37 & 50 & 25 & 112 & MI \\
\hline Liu, a & 1999 & 23 & 33 & 23 & 79 & 39 & 33 & 8 & 80 & $\mathrm{MI}$ \\
\hline Qiu, a & 1999 & 24 & 49 & 45 & 118 & 42 & 43 & 17 & 102 & CHD \\
\hline Tan & 1999 & 24 & 51 & 62 & 137 & 21 & 29 & 13 & 63 & CAD \\
\hline Lai, a & 1999 & 20 & 11 & 22 & 53 & 19 & 9 & 5 & 33 & CAD \\
\hline Saha & 1996 & 97 & 132 & 47 & 276 & 55 & 63 & 29 & 147 & CAD \\
\hline Dhar & 2012 & 33 & 103 & 51 & 187 & 103 & 113 & 39 & 255 & CAD \\
\hline Pandey & 2010 & 61 & 88 & 54 & 203 & 59 & 80 & 73 & 212 & \begin{tabular}{|l|} 
CAD \\
\end{tabular} \\
\hline Firouzabadi & 2012 & 25 & 34 & 41 & 100 & 17 & 53 & 21 & 91 & CAD \\
\hline Moradzadegan & 2014 & 21 & 69 & 51 & 141 & 95 & 180 & 94 & 369 & CAD \\
\hline Poorgholi & 2012 & 97 & 262 & 317 & 676 & 54 & 158 & 162 & 374 & CAD \\
\hline Wang & 1996 & 53 & 63 & 80 & 196 & 43 & 97 & 66 & 206 & MI \\
\hline European & & & & & & & & & & \\
\hline Guney & 2013 & 38 & 81 & 86 & 203 & 35 & 65 & 40 & 140 & CAD \\
\hline A-Larsen & 1997 & 46 & 89 & 43 & 178 & 1879 & 3494 & 1712 & 7085 & MI \\
\hline Arbustini, a & 1995 & 21 & 105 & 129 & 255 & 32 & 67 & 34 & 133 & CAD \\
\hline Arbustini, b & 1995 & 13 & 67 & 74 & 154 & 40 & 105 & 89 & 234 & MI \\
\hline Gardemann & 1998 & 221 & 517 & 328 & 1066 & 277 & 598 & 326 & 1201 & MI \\
\hline Kaski & 1996 & 13 & 28 & 28 & 69 & 16 & 33 & 24 & 73 & CAD \\
\hline Katsuya & 1995 & 91 & 210 & 121 & 422 & 93 & 202 & 111 & 406 & CHD \\
\hline Miettinen & 1994 & 12 & 43 & 27 & 82 & 10 & 22 & 18 & 50 & CHD \\
\hline Samani & 1996 & 154 & 321 & 209 & 684 & 120 & 259 & 158 & 537 & MI \\
\hline Schuster & 1995 & 34 & 60 & 44 & 138 & 35 & 86 & 41 & 162 & MI \\
\hline Wenzel & 1997 & 21 & 61 & 31 & 113 & 47 & 95 & 55 & 197 & $\mathrm{CHD}$ \\
\hline Mattu & 1995 & 69 & 181 & 154 & 404 & 159 & 375 & 288 & 822 & CAD \\
\hline Cambien, a & 1992 & 39 & 111 & 51 & 201 & 42 & 95 & 43 & 180 & MI \\
\hline Cambien, b & 1992 & 7 & 24 & 27 & 58 & 32 & 73 & 43 & 148 & MI \\
\hline Cambien, c & 1992 & 30 & 107 & 67 & 204 & 41 & 98 & 55 & 194 & MI \\
\hline Cambien, d & 1992 & 28 & 67 & 52 & 147 & 28 & 124 & 59 & 211 & MI \\
\hline Cambien, e & 1992 & 104 & 309 & 197 & 610 & 143 & 390 & 200 & 733 & MI \\
\hline American & & & & & & & & & & \\
\hline Marian & 2000 & 35 & 87 & 55 & 177 & 40 & 110 & 33 & 183 & CAD \\
\hline Lindpaintner & 1995 & 71 & 190 & 126 & 387 & 297 & 725 & 453 & 1475 & Ml \\
\hline Araujo & 2005 & 17 & 57 & 36 & 110 & 20 & 33 & 51 & 104 & \begin{tabular}{|l|l|}
$\mathrm{MI}$ \\
\end{tabular} \\
\hline
\end{tabular}

$\mathrm{CHD}=$ congenital heart defect; $\mathrm{MI}=$ myocardial infarction; $\mathrm{CAD}=$ coronary artery disease $; \mathrm{HWE}=$ Hardy-Weinberg equilibrium. 
Table 2. Meta-analysis for the entire database with the dominant (DD + ID vs II), recessive (DD vs ID + II), and homozygote (DD vs II) comparison models.

\begin{tabular}{l|l|c|c|c|c|c|c}
\hline Analysis model & Analysis method & \multicolumn{3}{|c|}{ Heterogeneity } & \multicolumn{3}{c}{ OR } \\
\cline { 3 - 8 } & & $\mathrm{I}^{2}(\%)$ & $\mathrm{P}$ value & Overall & Lower & Upper & $\mathrm{P}$ value \\
\hline Dominant & Random & 70.60 & $<0.001$ & 2.114 & 1.900 & 2.352 & $<0.001$ \\
\hline Recessive & Random & 68.30 & $<0.001$ & 1.669 & 1.495 & 1.864 & $<0.001$ \\
\hline Homozygote & Random & 67.70 & $<0.001$ & 1.877 & 1.639 & 2.151 & $<0.001$ \\
\hline
\end{tabular}

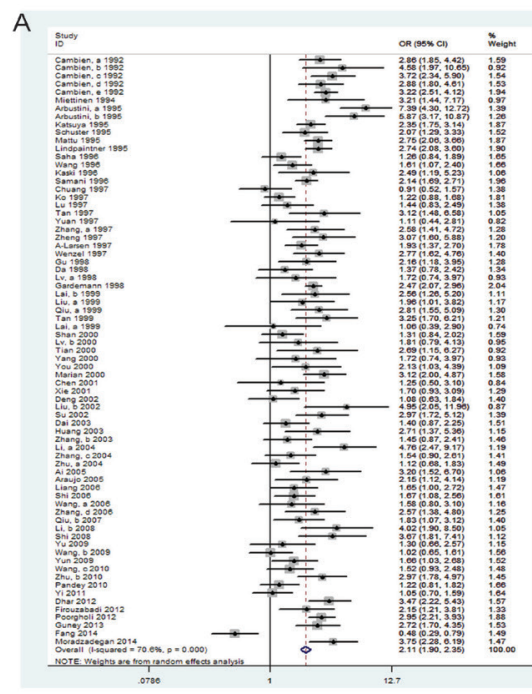

B suo

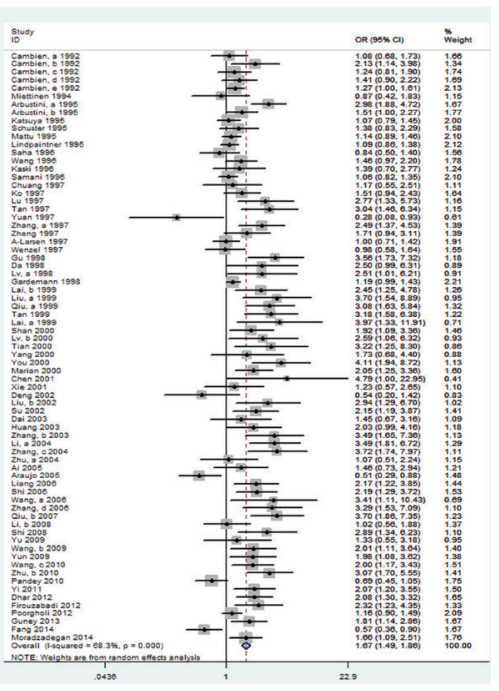

C
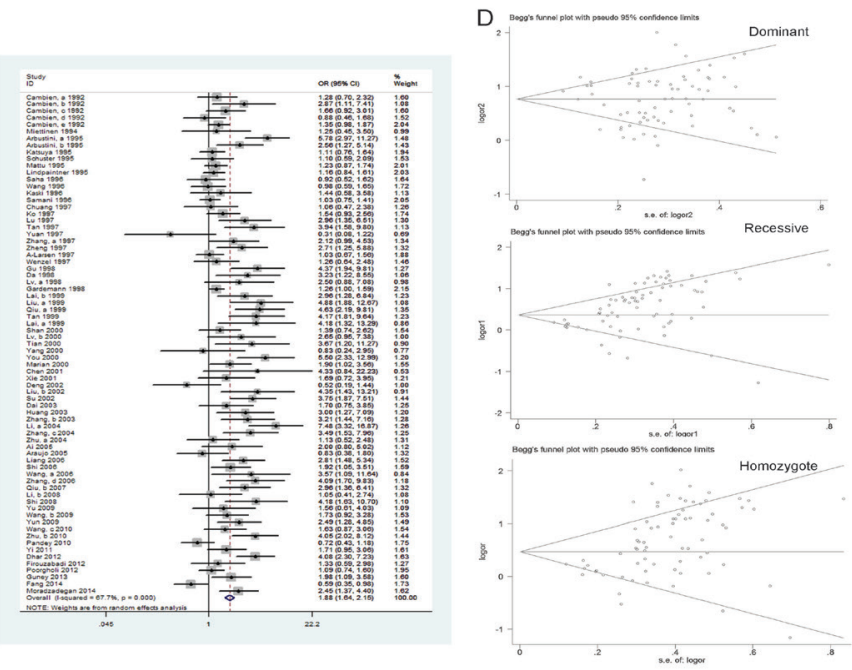

Figure 2. Forest plots of all individual studies in the overall meta-analysis. Odds ratios (ORs) are plotted with the corresponding $95 \%$ confidence interval $(95 \% \mathrm{Cl})$ for the association between ACE I/D polymorphism and HDs by using: A. dominant model (DD + ID vs II); B. recessive model (DD vs ID + II); and C. homozygote model (DD vs II). D. Funnel plots of all individual studies in the overall meta-analysis. Studies that evaluated the association of ACE I/D polymorphism and HDs are plotted with logarithm of ORs along the vertical axis, and logarithm of standard error (S.E.) of the ORs along the horizontal axis. 


\section{ACE I/D polymorphisms and HD risk in the subgroups based on ethnicity}

We performed a meta-analysis on three subgroups based on ethnicity: Asian, European, and American. Similar to previous analysis, we applied all three comparison models (dominant, recessive, and homozygote) to each subgroup.

Results from the analysis of the Asian subgroup are shown in Table 3. For the dominant model (DD + ID vs II), the OR was $1.445(95 \% \mathrm{Cl}=1.278-1.635, \mathrm{P}<0.001)$, heterogeneity index $\mathrm{I}^{2}=58 \%$. For the recessive model (DD vs ID + II), the OR was $1.949(95 \% \mathrm{Cl}=1.68-2.261, \mathrm{P}<$ 0.001 ), heterogeneity index $\mathrm{I}^{2}=64 \%$. For the homozygote comparison (DD vs II), the OR was $2.166(95 \% \mathrm{Cl}=1.806-2.597, \mathrm{P}<0.001)$, heterogeneity index $\mathrm{I}^{2}=66.6 \%$. Results from all three models suggested that ACE I/D polymorphism was significantly associated with high HD risk in the Asian subpopulation. Figure $3 \mathrm{~A}-\mathrm{C}$ displays the meta-analysis results for the dominant, recessive, and homozygote models, respectively. Funnel plots for all three comparison models showed that no obvious publication bias was introduced (Figure 3D).

Table 3. Meta-analysis for subgroups based on ethnicity with the dominant (DD + ID vs II), recessive (DD vs ID + II), and homozygote (DD vs II) comparison models.

\begin{tabular}{|c|c|c|c|c|c|c|c|c|}
\hline \multirow{2}{*}{ Subgroups } & \multirow[t]{2}{*}{ Analysis model } & \multirow{2}{*}{ Analysis method } & \multicolumn{2}{|c|}{ Heterogeneity } & \multicolumn{4}{|c|}{ OR } \\
\hline & & & $\mathrm{I}^{2}(\%)$ & $P$ value & Overall & Lower & Upper & $P$ value \\
\hline \multirow[t]{3}{*}{ Asian } & Dominant & Random & 58.00 & $<0.001$ & 1.445 & 1.278 & 1.635 & $<0.001$ \\
\hline & Recessive & Random & 64.00 & $<0.001$ & 1.949 & 1.68 & 2.261 & $<0.001$ \\
\hline & Homozygote & Random & 66.60 & $<0.001$ & 2.166 & 1.806 & 2.597 & $<0.001$ \\
\hline \multirow[t]{3}{*}{ European } & Dominant & Random & 43.60 & 0.028 & 1.224 & 1.063 & 1.409 & 0.005 \\
\hline & Recessive & Random & 41.90 & 0.036 & 1.270 & 1.128 & 1.43 & $<0.001$ \\
\hline & Homozygote & Fixed & 16.30 & 0.263 & 4.050 & 3.658 & 4.483 & $<0.001$ \\
\hline \multirow[t]{3}{*}{ American } & Dominant & Fixed & 0.00 & 0.929 & 1.143 & 0.903 & 1.448 & 0.267 \\
\hline & Recessive & Random & 85.40 & 0.001 & 1.055 & 0.558 & 1.994 & 0.859 \\
\hline & Homozygote & Fixed & 32.70 & 0.226 & 1.224 & 0.934 & 1.604 & 0.142 \\
\hline
\end{tabular}

Results from analysis of the European subgroup are shown in Table 3. For the dominant model (DD + ID vs II), the OR was $1.224(95 \% \mathrm{Cl}=1.063-1.409, \mathrm{P}=0.005)$, heterogeneity index $\mathrm{I}^{2}=43.6 \%$. For the recessive model (DD vs ID + II), the OR was $1.27(95 \% \mathrm{Cl}=1.128-1.43, \mathrm{P}<$ 0.001 ), heterogeneity index $\mathrm{I}^{2}=41.9 \%$. For the homozygote comparison (DD vs II), the OR was $4.05(95 \% \mathrm{Cl}=3.658-4.483, \mathrm{P}<0.001)$, heterogeneity index $\mathrm{I}^{2}=16.3 \%$. Results from all three models pointed to significant association between ACE I/D polymorphism and high HD risk in the European subgroup. Figure 4A-C shows the meta-analysis results for the dominant, recessive, and homozygote models, respectively. Funnel plots for all three comparison models indicated that no obvious publication bias was introduced (Figure 4D).

Results from the analysis for American subgroup are shown in Table 3. For dominant model (DD+ID vs II), the OR was $1.143(95 \% \mathrm{Cl}=0.903-1.448, \mathrm{P}=0.267)$, heterogeneity index $\mathrm{I}^{2}$ $=0 \%$. For recessive model (DD vs ID+II), the OR was $1.055(95 \% \mathrm{Cl}=0.558-1.994, \mathrm{P}=0.859)$, heterogeneity index $\mathrm{I}^{2}=85.4 \%$. For homozygote comparison (DD vs II), the OR was $1.224(95 \% \mathrm{Cl}$ $=0.934-1.604, \mathrm{P}=0.142$ ), heterogeneity index $\mathrm{I}^{2}=32.7 \%$. The results from all three models suggested no significant association between ACE I/D polymorphism and high HD risk in the American subgroup. Figure 5A-C displayed the meta-analysis results for dominant, recessive, and homozygote models, respectively. Funnel plots for all three comparison models showed that no obvious publication bias was introduced (Figure 5D). 
A

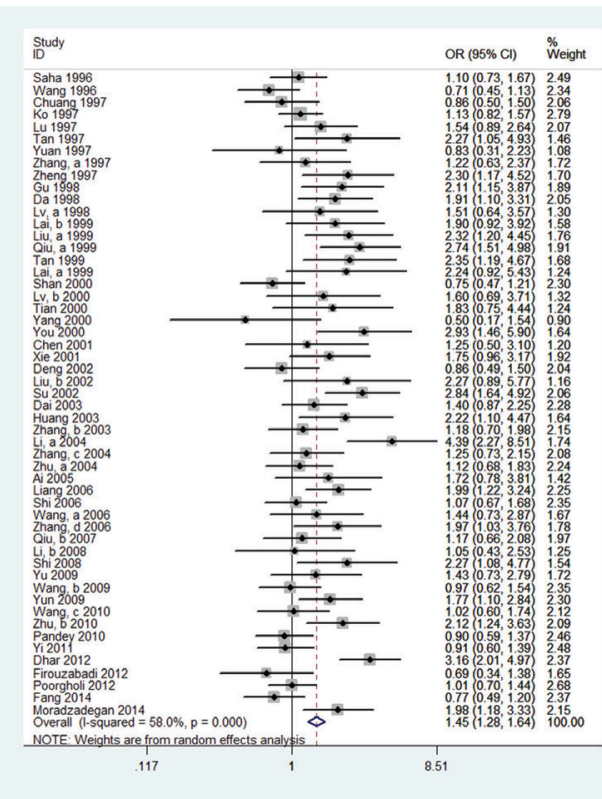

C

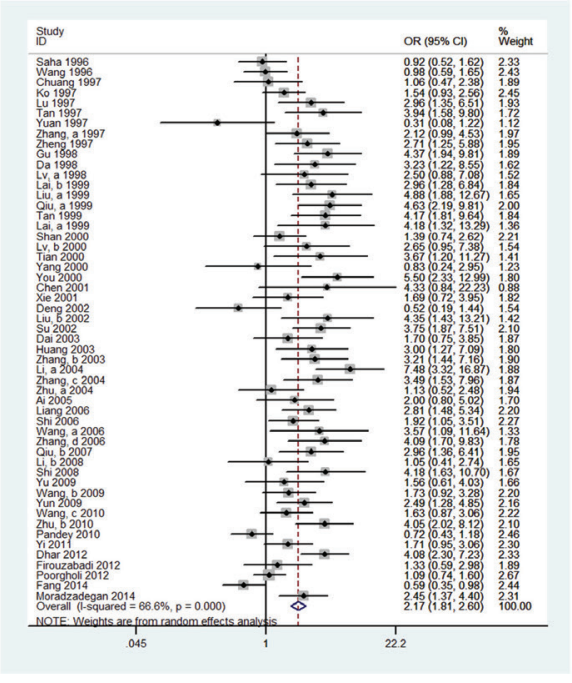

B

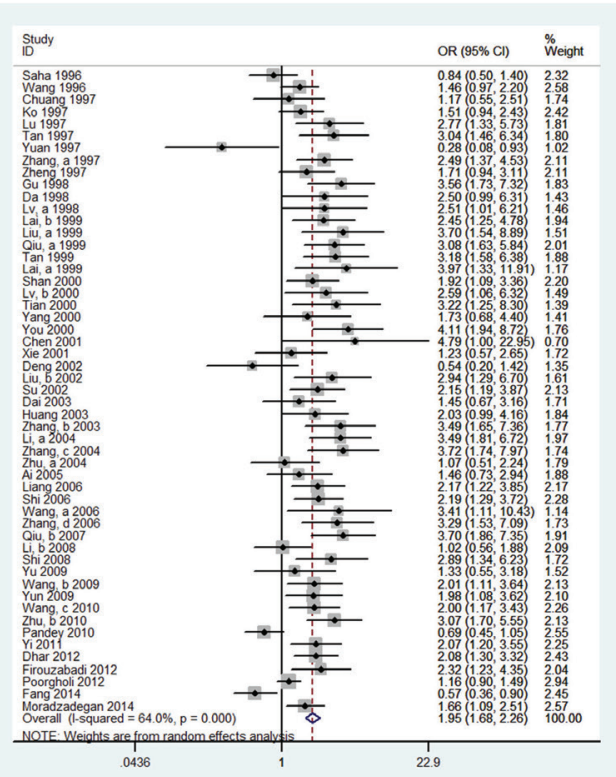

$\mathrm{D}$
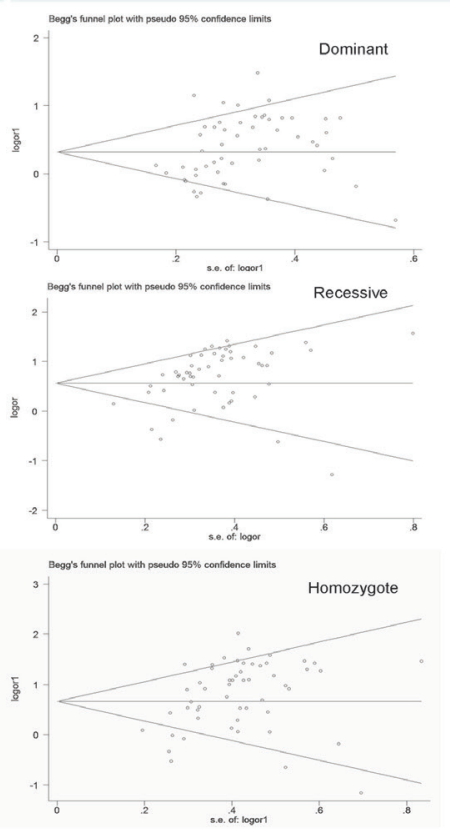

Figure 3. Forest plots of all individual studies in the Asian subgroup meta-analysis. Odds ratios (ORs) are plotted with the corresponding $95 \%$ confidence interval $(95 \% \mathrm{Cl})$ for the association between ACE I/D polymorphism and HDs by using: A. dominant model (DD + ID vs II); B. recessive model (DD vs ID + II); and C. homozygote model (DD vs II). D. Funnel plots of all individual studies in the Asian subgroup meta-analysis. Studies that evaluated the association between ACE I/D polymorphism and HDs are plotted with logarithm of ORs along the vertical axis, and logarithm of standard error (S.E.) of the ORs along the horizontal axis. 
A

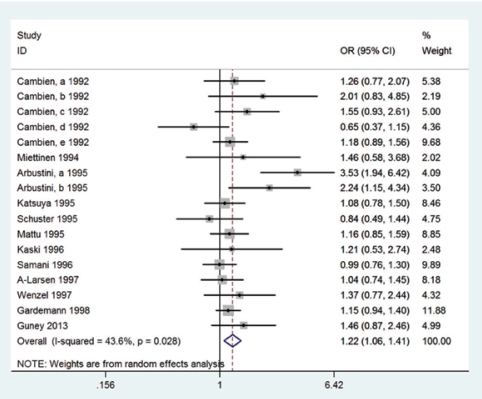

C

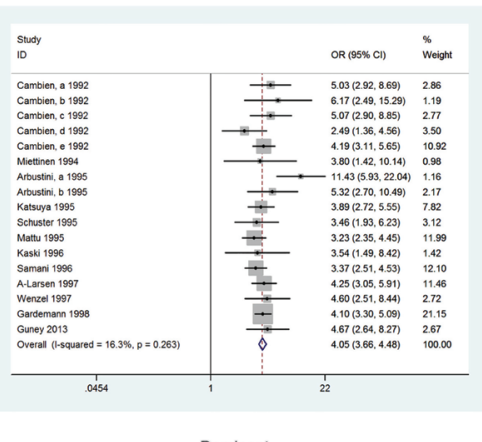

D

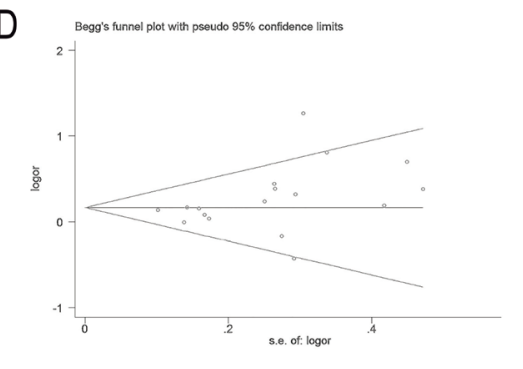

Homozygote

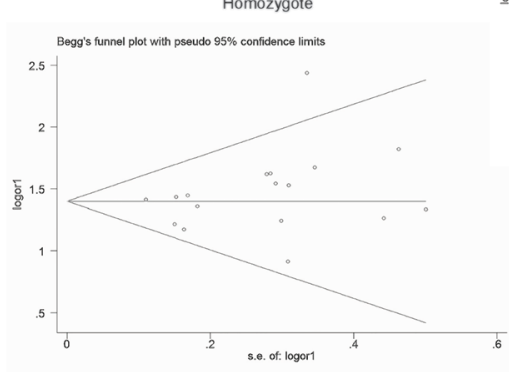

B

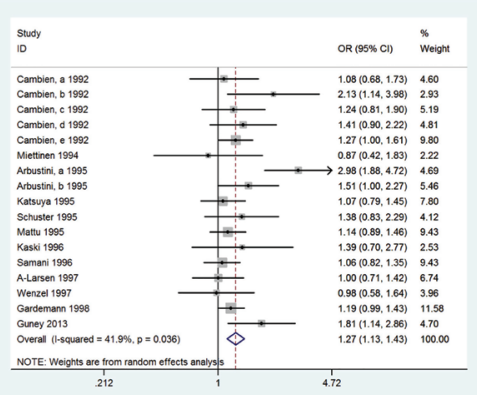

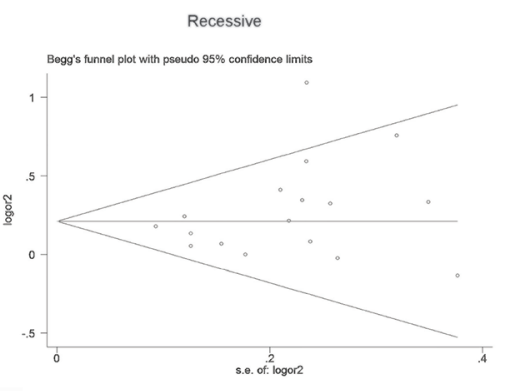

Figure 4. Forest plots of all individual studies in the European subgroup meta-analysis. Odds ratios (ORs) are plotted with the corresponding $95 \%$ confidence interval $(95 \% \mathrm{Cl})$ for the association between ACE I/D polymorphism and HDs by using: A. dominant model (DD + ID vs II); B. recessive model (DD vs ID + II); and C. homozygote model (DD vs II). D. Funnel plots of all individual studies in the European subgroup meta-analysis. Studies that evaluated the association between ACE I/D polymorphism and HDs are plotted with logarithm of ORs along the vertical axis, and logarithm of standard error (S.E.) of the ORs along the horizontal axis. 

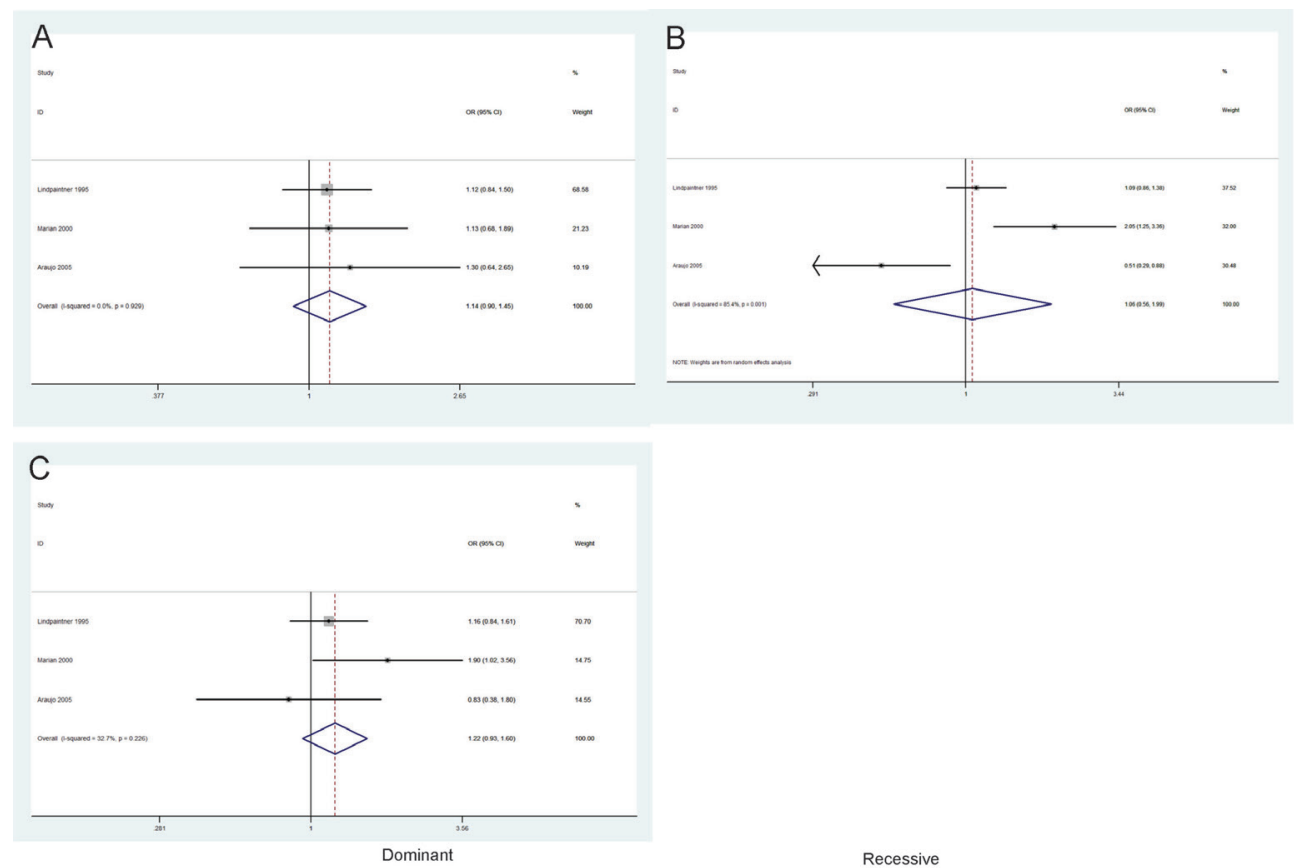

D
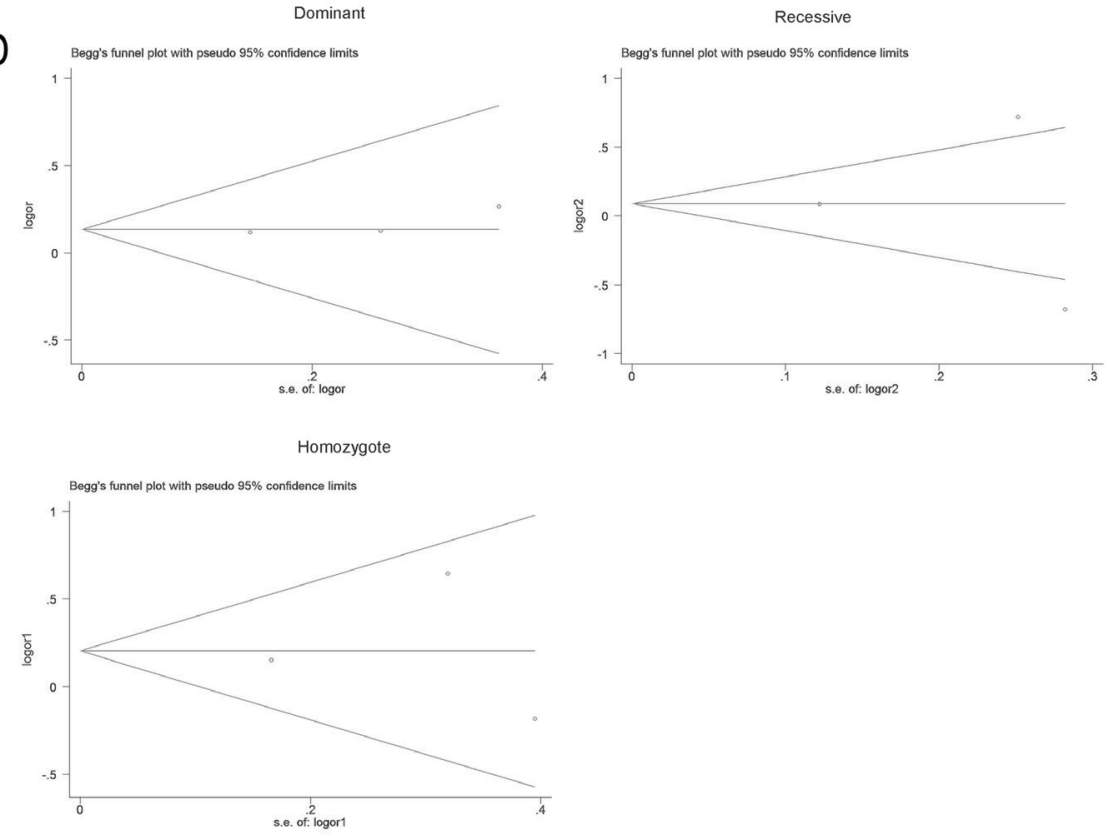

Figure 5. Forest plots of all individual studies in the American subgroup meta-analysis. Odds ratios (ORs) are plotted with the corresponding $95 \%$ confidence interval $(95 \% \mathrm{Cl})$ for the association between ACE I/D polymorphism and HDs by using: A. dominant model (DD + ID vs II); B. recessive model (DD vs ID + II); and C. homozygote model (DD vs II). D. Funnel plots of all individual studies in the American subgroup meta-analysis. Studies that evaluated the association between ACE I/D polymorphism and HDs are plotted with logarithm of ORs along the vertical axis, and logarithm of standard error (S.E.) of the ORs along the horizontal axis. 


\section{ACE I/D polymorphisms and HD risk in the subgroups based on disease type}

We also performed similar meta-analysis on three subgroups based on disease type: CHD, CAD, and MI.

Results from the analysis for the CHD subgroup are presented in Table 4. For the dominant model (DD + ID vs II), the OR was $1.322(95 \% \mathrm{Cl}=1.113-1.571, \mathrm{P}=0.001)$, heterogeneity index $\mathrm{I}^{2}=48.7 \%$. For the recessive model (DD vs ID + II), the OR was $1.714(95 \% \mathrm{Cl}=1.327-2.213$, $\mathrm{P}<0.001$ ), heterogeneity index $\mathrm{I}^{2}=70.2 \%$. For the homozygote comparison (DD vs II), the OR was $1.906(95 \% \mathrm{Cl}=1.436-2.528, \mathrm{P}<0.001)$, heterogeneity index $\mathrm{I}^{2}=66.5 \%$. These results suggested that there is significant association between ACE I/D polymorphism and high HD risk in the CHD subgroup. Figure 6A-C displays the meta-analysis results for the dominant, recessive, and homozygote models, respectively. Funnel plots for all three comparison models showed that no obvious publication bias was introduced (Figure 6D).

Table 4. Meta-analysis for subgroups based on disease type with the dominant (DD + ID vs II), recessive (DD vs ID + II), and homozygote (DD vs II) comparison models.

\begin{tabular}{|c|c|c|c|c|c|c|c|c|}
\hline & \multirow[t]{2}{*}{ Analysis Model } & \multirow{2}{*}{$\begin{array}{l}\text { Analysis } \\
\text { Method }\end{array}$} & \multicolumn{3}{|c|}{ Heterogeneity } & \multicolumn{3}{|c|}{ OR } \\
\hline & & & $\mathrm{I}^{2}(\%)$ & $\mathrm{P}$ value & Overall & Lower & Upper & $P$ value \\
\hline \multirow[t]{3}{*}{ CHD } & Dominant & Random & 48.70 & 0.007 & 1.322 & 1.113 & 1.571 & 0.001 \\
\hline & Recessive & Random & 70.20 & $<0.001$ & 1.714 & 1.327 & 2.213 & $<0.001$ \\
\hline & Homozygote & Random & 66.50 & $<0.001$ & 1.906 & 1.436 & 2.528 & $<0.001$ \\
\hline \multirow[t]{3}{*}{ CAD } & Dominant & Random & 68.80 & $<0.001$ & 1.752 & 1.445 & 2.125 & $<0.001$ \\
\hline & Recessive & Random & 68.80 & $<0.001$ & 1.752 & 1.445 & 2.125 & $<0.001$ \\
\hline & Homozygote & Random & 71.70 & $<0.001$ & 1.997 & 1.558 & 2.559 & $<0.001$ \\
\hline \multirow[t]{3}{*}{$\mathrm{Ml}$} & Dominant & Random & 45.50 & 0.006 & 1.308 & 1.140 & 1.500 & $<0.001$ \\
\hline & Recessive & Random & 66.40 & $<0.001$ & 1.543 & 1.313 & 1.814 & $<0.001$ \\
\hline & Homozygote & Random & 63.10 & $<0.001$ & 1.691 & 1.386 & 2.063 & $<0.001$ \\
\hline
\end{tabular}

Results from the analysis for CAD subgroup are shown in Table 4. For the dominant model $\left(\mathrm{DD}+\mathrm{ID}\right.$ vs II), the OR was $1.752(95 \% \mathrm{Cl}=1.445-2.125, \mathrm{P}<0.001)$, heterogeneity index $\mathrm{I}^{2}=$ $68.8 \%$. For the recessive model (DD vs ID $+\mathrm{II})$, the OR was $1.752(95 \% \mathrm{Cl}=1.445-2.125, \mathrm{P}<$ 0.001 ), heterogeneity index $\mathrm{I}^{2}=68.8 \%$. For the homozygote comparison (DD vs II), the OR was $1.997(95 \% \mathrm{Cl}=1.558-2.559, \mathrm{P}<0.001)$, heterogeneity index $\mathrm{I}^{2}=71.7 \%$. The suggested that there is a significant association between ACE I/D polymorphism and high HD risk in the CAD subgroup. Figure 7A-C shows the meta-analysis results for the dominant, recessive, and homozygote models, respectively. Funnel plots for all three comparison models suggested that no obvious publication bias was present (Figure 7D).

Results from the analysis for the MI subgroup are shown in Table 4. For the dominant model (DD + ID vs II), the OR was $1.308(95 \% \mathrm{Cl}=1.14-1.5, \mathrm{P}<0.001)$, heterogeneity index I2 $=45.5 \%$. For the recessive model (DD vs ID + II), the OR was $1.543(95 \% \mathrm{Cl}=1.313-1.814, \mathrm{P}$ $<0.001$ ), heterogeneity index $\mathrm{I}^{2}=66.4 \%$. For the homozygote comparison (DD vs II), the OR was $1.691(95 \% \mathrm{Cl}=1.386-2.063, \mathrm{P}<0.001)$, heterogeneity index $\mathrm{I}^{2}=63.1 \%$. These results indicated that ACE I/D polymorphism is not associated with high HD risk in the MI subgroup. Figure $8 \mathrm{~A}-\mathrm{C}$ shows the meta-analysis results for the dominant, recessive, and homozygote models, respectively. Funnel plots for all three comparison models showed that no obvious publication bias was introduced (Figure 8D). 


\section{A}

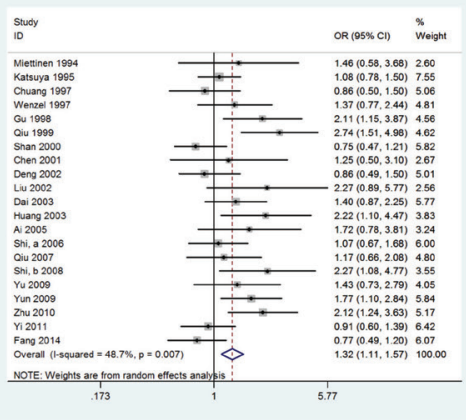

C

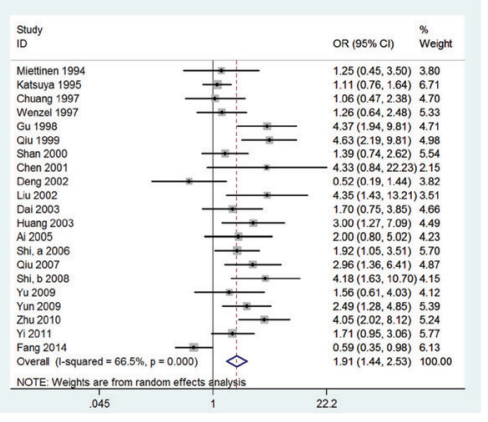

Dominant

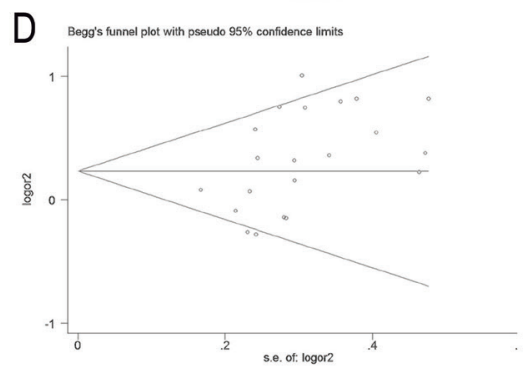

Homozygote

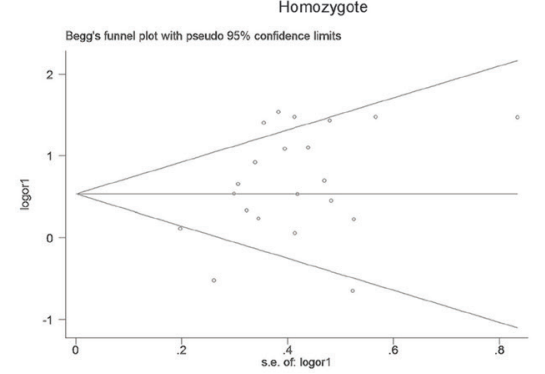

B stos

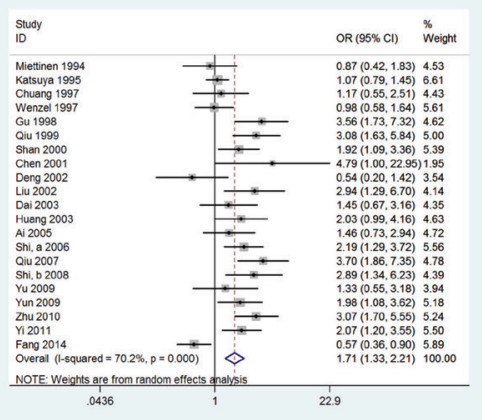

Recessive

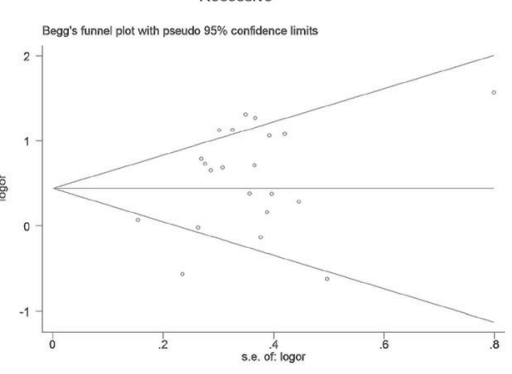

Figure 6. Forest plots of all individual studies in the CHD subgroup meta-analysis. Odds ratios (ORs) are plotted with the corresponding $95 \%$ confidence interval $(95 \% \mathrm{Cl})$ for the association between ACE I/D polymorphism and HDs by using: A. dominant model (DD + ID vs II); B. recessive model (DD vs ID + II); and C. homozygote model (DD vs II). D. Funnel plots of all individual studies in the CHD subgroup meta-analysis. Studies that evaluated the association between ACE I/D polymorphism and HDs are plotted with logarithm of ORs along the vertical axis, and logarithm of standard error (S.E.) of the ORs along the horizontal axis. 
A

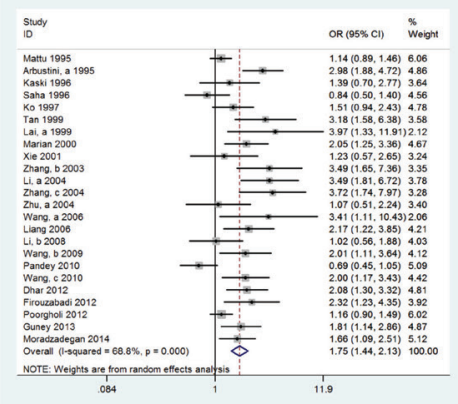

C

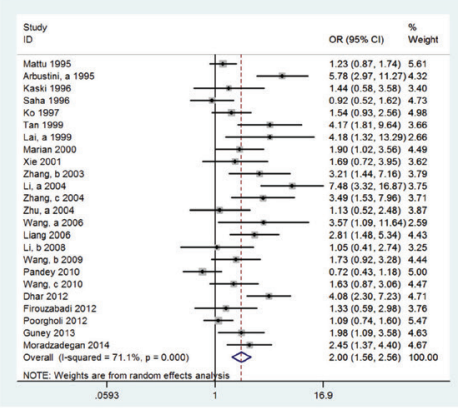

D

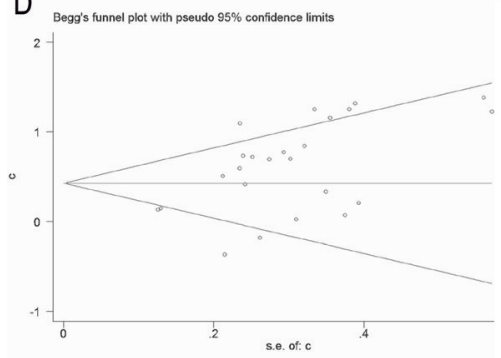

Homozygote

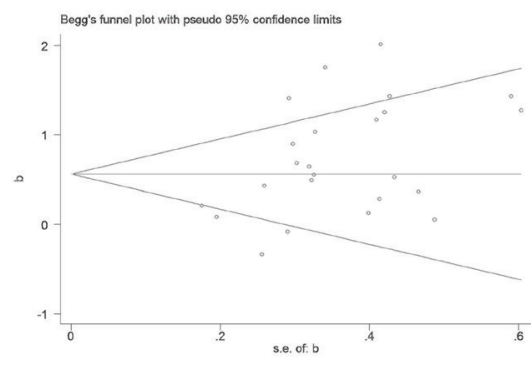

6
B

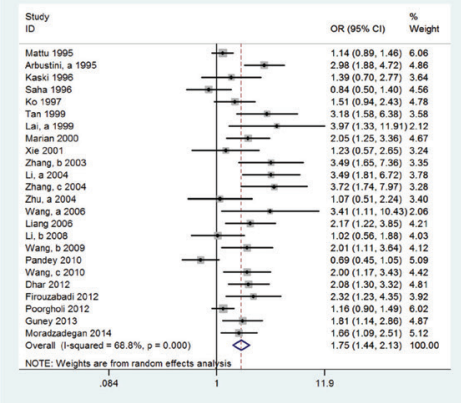

Recessive

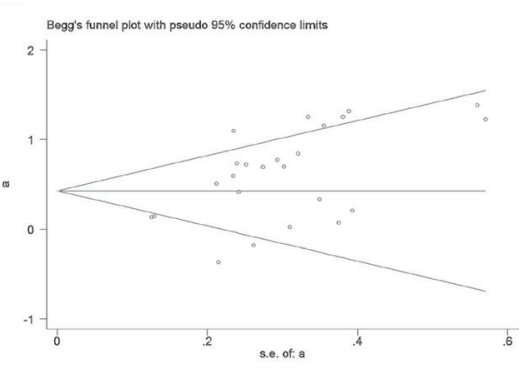

Figure 7. Forest plots of all individual studies in the CAD subgroup meta-analysis. Odds ratios (ORs) are plotted with the corresponding $95 \%$ confidence interval $(95 \% \mathrm{Cl})$ for the association between ACE I/D polymorphism and HDs by using: A. dominant model (DD + ID vs II); B. recessive model (DD vs ID + II); and C. homozygote model (DD vs II). D. Funnel plots of all individual studies in the CAD subgroup meta-analysis. Studies that evaluated the association between ACE I/D polymorphism and HDs are plotted with logarithm of ORs along the vertical axis, and logarithm of standard error (S.E.) of the ORs along the horizontal axis. 

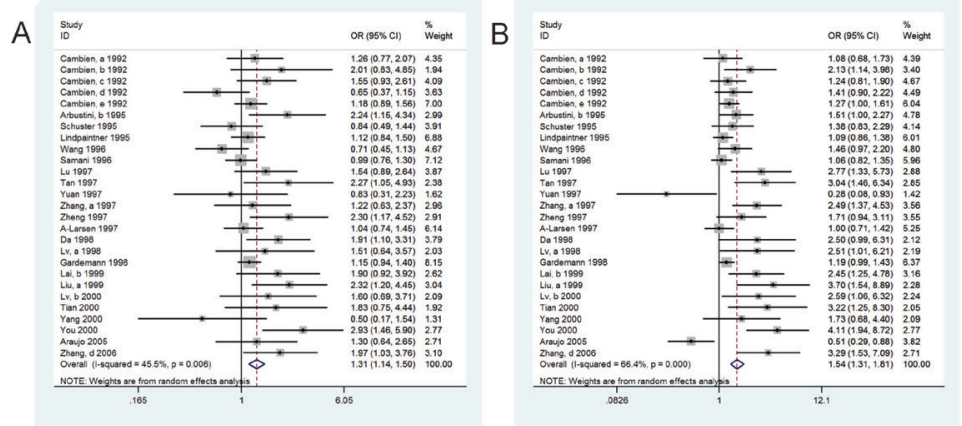

C

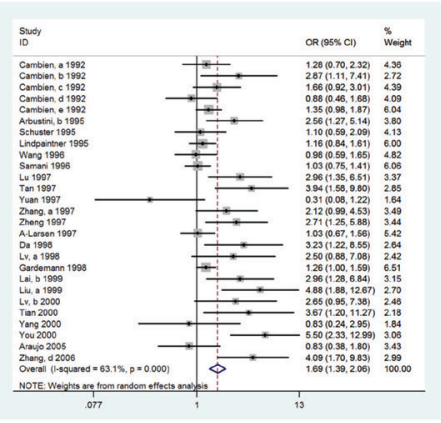

D

Dominant
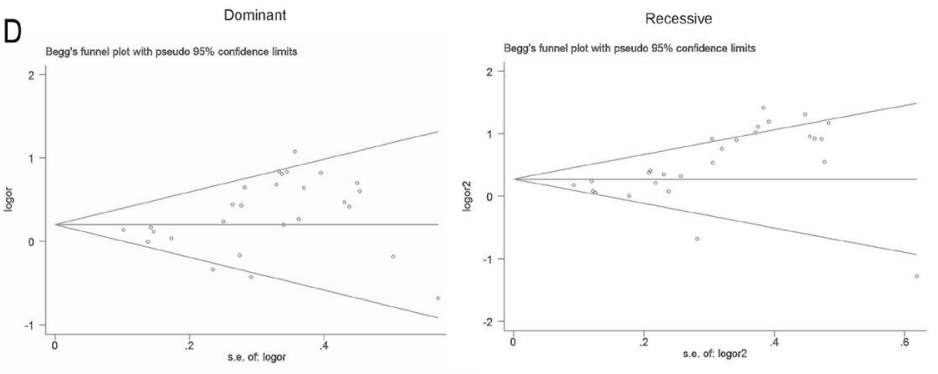

Homozygote

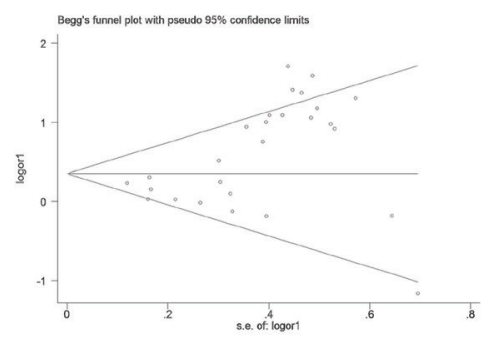

Figure 8. Forest plots of all individual studies in the MI subgroup meta-analysis. Odds ratios (ORs) are plotted with the corresponding $95 \%$ confidence interval $(95 \% \mathrm{Cl})$ for the association between ACE I/D polymorphism and HDs by using: A. dominant model (DD + ID vs II); B. recessive model (DD vs ID + II); and C. homozygote model (DD vs II). D. Funnel plots of all individual studies in the Ml subgroup meta-analysis. Studies that evaluated the association between ACE I/D polymorphism and HDs are plotted with logarithm of ORs along the vertical axis and logarithm of standard error (S.E.) of the ORs along the horizontal axis. 


\section{DISCUSSION}

Our meta-analysis of 75 studies demonstrated that individuals with the DD or ID genotype have a $111.4 \%$ higher risk of suffering $\mathrm{HD}$ as compared with individuals with the II genotype. Furthermore, individuals with the DD genotype have a $66.9 \%$ higher risk of HD as compared with ID or II, and an $87.7 \%$ higher risk of HD as compared with the II genotype. From our subgroup analyses based on ethnicity, we found that Asian and European subgroups with the DD genotype of ACE show a higher risk of heart diseases while the American subgroup show no such association. From our subgroup analyses based on disease type, we found that all three subgroups (CHD, CAD, and MI) show an association between the DD genotype of ACE and high HD risk. These findings are in good accordance with multiple studies conducted previously (Bautista et al., 2004; Pulla Reddy et al., 2010; Sobti et al., 2010; Masud and Qureshi, 2011; Chen et al., 2013). The exception found in the American subgroup is most likely due to limited sample size. In addition, in all subgroup analyses, homozygous comparison model produced the highest ORs as compared with the dominant and recessive models, which further indicates that the D allele of ACE is a risk allele associated with HDs. So far, this study is the most comprehensive up-to-date meta-analysis regarding the association between ACE I/D polymorphism and HD risk.

Meta-analysis has been widely used as a useful statistical method in biomedical research. It is particularly useful in elucidating subjects such as the association between ACE I/D polymorphism and HD risk, which has been extensively studied and debated among various research groups. In the literature, there are currently three meta-analyses evaluating the association between ACE I/D polymorphism and CHD/CAD risk (Jiang et al., 2006; Zintzaras et al., 2008; Zhou et al., 2012) and two meta-analyses evaluating the association between ACE I/D polymorphism and MI risk (Samani et al., 1996; Chen et al., 2013). Aside from these meta-analyses, many epidemiological studies have been conducted to assess the association between ACE I/D polymorphism and CHD, CAD or $\mathrm{MI}$ risks in different populations. Here for the first time, we treated all three types of HDs as a whole and performed a meta-analysis to explore the association between ACE I/D polymorphism and HDs. Our study, as the most comprehensive meta-analysis, confirms the significant association between ACE I/D polymorphism and HD risks among the general, Asian, and European population, as reported by various individual epidemiological studies. It should be noted that several previous studies indicated there was no association between the DD genotype of ACE I/D polymorphism and HD risks (Marques-Vidal et al., 2003; Andrikopoulos et al., 2004; Zakrzewski-Jakubiak et al., 2008; Rallidis et al., 2009; Bai et al., 2012). Nevertheless, our study is based on a great number of recently published studies, and is able to achieve sufficient statistical power to detect the effect of ACE I/D polymorphism on HD risks. Considering that HD is a complex disease with multi-factorial traits, the influence of ACE I/D polymorphism on HDs may vary between different geographical areas or different patient subgroups. Gene products and environmental factors may exert different influences on the development and progression of HDs. Therefore, it is possible that the effect of the DD-ACE genotype on HDs could not be detected in these previous studies due to limited sample selection.

Between-study heterogeneity is a very common issue in the meta-analysis of association studies. It was also observed in our study for both the overall and subgroup analyses, which may weaken the power of the analysis. It may be a result of various factors such as differences in study designs, environmental backgrounds, genetic constitution, or sample selection between studies. 


\section{Conflicts of interest}

The authors declare no conflict of interest.

\section{REFERENCES}

Ai LM (2005). Association between angiotensin converting enzyme gene polymorphism and coronary heart disease in subjects with Uyghur nationality. J. Shanxi Med. Univ. 36: 580-583.

Andrikopoulos GK, Richter DJ, Needham EW, Tzeis SE, et al. (2004). The paradoxical association of common polymorphisms of the renin-angiotensin system genes with risk of myocardial infarction. Eur. J. Cardiovasc. Prev. Rehabil. 11: 477-483.

Araújo MA, Goulart LR, Cordeiro ER, Gatti RR, et al. (2005). Genotypic interactions of renin-angiotensin system genes in myocardial infarction. Int. J. Cardiol. 103: 27-32. http://dx.doi.org/10.1016/j.ijcard.2004.07.009

Bai Y, Wang L, Hu S and Wei Y (2012). Association of angiotensin-converting enzyme I/D polymorphism with heart failure: a meta-analysis. Mol. Cell. Biochem. 361: 297-304. http://dx.doi.org/10.1007/s11010-011-1115-8

Bautista LE, Ardila ME, Gamarra G, Vargas Cl, et al. (2004). Angiotensin-converting enzyme gene polymorphism and risk of myocardial infarction in Colombia. Med. Sci. Monit. 10: CR473-CR479.

Chen Y, Dong S, He M, Qi T, et al. (2013). Angiotensin-converting enzyme insertion/deletion polymorphism and risk of myocardial infarction in an updated meta-analysis based on 34993 participants. Gene 522: 196-205. http://dx.doi. org/10.1016/j.gene.2013.03.076

Dai $Y$ (2003). The I/D genetic polymorphism of the plasminogen angiotensin converting enzyme gene is associated with plasma activity and the risk of coronary artery disease. Chin. Circ. J. 18: 25-28.

Dai HL, Guo Y, Guang XF, Xiao ZC, et al. (2013). The changes of serum angiotensin-converting enzyme 2 in patients with pulmonary arterial hypertension due to congenital heart disease. Cardiology 124: 208-212. http://dx.doi. org/10.1159/000346884

Danser AH, Schalekamp MA, Bax WA, van den Brink AM, et al. (1995). Angiotensin-converting enzyme in the human heart. Effect of the deletion/insertion polymorphism. Circulation 92: 1387-1388. http://dx.doi.org/10.1161/01.CIR.92.6.1387

Dhar S, Chatterjee S, Ray S, Dutta A, et al. (2010). Polymorphisms of methylenetetrahydrofolate reductase gene as the genetic predispositions of coronary artery diseases in eastern India. J. Cardiovasc. Dis. Res. 1: 152-157. http://dx.doi. org/10.4103/0975-3583.70922

Dries DL, Exner DV, Gersh BJ, Cooper HA, et al. (1999). Racial differences in the outcome of left ventricular dysfunction. $N$. Engl. J. Med. 340: 609-616. http://dx.doi.org/10.1056/NEJM199902253400804

Fang C, Ren X, Zhou H, Gong ZC, et al. (2014). Effects of eNOS rs1799983 and ACE rs4646994 polymorphisms on the therapeutic efficacy of salvianolate injection in Chinese patients with coronary heart disease. Clin. Exp. Pharmacol. Physiol. 41: 558-564. http://dx.doi.org/10.1111/1440-1681.12257

Firouzabadi N, Tajik N, Bahramali E, Bakhshandeh H, et al. (2012). Association of angiotensin-converting enzyme polymorphism with coronary artery disease in Iranian patients with unipolar depression. Clin. Biochem. 45: 1347-1352. http://dx.doi. org/10.1016/j.clinbiochem.2012.05.033

Jiang X, Dong SH, Luo LJ, Sun Y, et al. (2006). [Meta-analysis of association of deletion allele of angiotensin-converting enzyme gene with coronary heart disease in China]. Zhonghua Yu Fang Yi Xue Za Zhi 40: 351-354.

$\mathrm{Li} \mathrm{J}$ (2004). Association of angiotensin converting enzyme gene with coronary heart disease, essential hypertension and type 2 diabetic mellitus in chinese population. Chin. J. Misdiagnost. 4: 1595-1597.

Li LH (2008). Study on the relationship between ACE polymorphism and coronary heart disease. Shandong Med. J. 48: 41-42.

Marques-Vidal P, Bongard V, Ruidavets JB, Fauvel J, et al. (2003). Effect of apolipoprotein E alleles and angiotensinconverting enzyme insertion/deletion polymorphisms on lipid and lipoprotein markers in middle-aged men and in patients with stable angina pectoris or healed myocardial infarction. Am. J. Cardiol. 92: 1102-1105. http://dx.doi.org/10.1016/j. amicard.2003.06.008

Masud R and Qureshi IZ (2011). Tetra primer ARMS-PCR relates folate/homocysteine pathway genes and ACE gene polymorphism with coronary artery disease. Mol. Cell. Biochem. 355: 289-297. http://dx.doi.org/10.1007/s11010-011$\underline{0866-6}$

Mi X, Eskridge KM, George V and Wang D (2011). Structural equation modeling of gene-environment interactions in coronary heart disease. Ann. Hum. Genet. 75: 255-265.

Moradzadegan A, Vaisi-Raygani A, Nikzamir A and Rahimi Z (2015). Angiotensin converting enzyme insertion/deletion (I/D) (rs4646994) and Vegf polymorphism (+405G/C; rs2010963) in type Il diabetic patients: Association with the risk of coronary artery disease. J. Renin Angiotensin Aldosterone Syst. 16: 672-680. http://dx.doi.org/10.1177/1470320313497819 
Negi S and Anand A (2010). Atherosclerotic coronary heart disease-epidemiology, classification and management. Cardiovasc. Hematol. Disord. Drug Targets 10: 257-261. http://dx.doi.org/10.2174/187152910793743832

Pandey U, Kumari R, Nath B, Ganesh S, et al. (2011). Association of angiotensin-converting enzyme, methylene tetrahydrofolate reductase and paraoxonase gene polymorphism and coronary artery disease in an Indian population. Cardiol. J. 18: 385-394.

Pulla Reddy B, Srikanth Babu BM, Venkata Karunakar K, Yasovanthi J, et al. (2010). Angiotensin-converting enzyme gene variant and its levels: risk factors for myocardial infarction in a South Indian population. Singapore Med. J. 51: 576-581.

Rallidis LS, Gialeraki A, Varounis C, Dagres N, et al. (2009). Lack of association of angiotensin-converting enzyme insertion/deletion polymorphism and myocardial infarction at very young ages. Biomarkers 14: 401-405. http://dx.doi. org/10.1080/13547500903039966

Rigat B, Hubert C, Corvol P and Soubrier F (1992). PCR detection of the insertion/deletion polymorphism of the human angiotensin converting enzyme gene (DCP1) (dipeptidyl carboxypeptidase 1). Nucleic Acids Res. 20: 1433. http://dx.doi. org/10.1093/nar/20.6.1433-a

Samani NJ, Thompson JR, O'Toole L, Channer K, et al. (1996). A meta-analysis of the association of the deletion allele of the angiotensin-converting enzyme gene with myocardial infarction. Circulation 94: 708-712. http://dx.doi.org/10.1161/01. CIR.94.4.708

Sekuri C, Cam FS, Ercan E, Tengiz I, et al. (2005). Renin-angiotensin system gene polymorphisms and premature coronary heart disease. J. Renin Angiotensin Aldosterone Syst. 6: 38-42. http://dx.doi.org/10.3317/jraas.2005.005

Sobti RC, Maithil N, Thakur H, Sharma Y, et al. (2010). Association of ACE and FACTOR VII gene variability with the risk of coronary heart disease in north Indian population. Mol. Cell. Biochem. 341: 87-98. http://dx.doi.org/10.1007/s11010-010$\underline{0440-7}$

Wang SQ (2010). Relationship between angiotensin-converting enzyme and angiotensinogen gene polymorphism and coronary heart disease. J. Nanchang Univ. 50: 8-11.

Wang XH (2009). Correlation of ace gene polymorphisms with coronary heart disease and lipids in Hainan Li Ethnics. China Trop. Med. 9: 1987-1988.

Yang A (2000). Analysis of angiotensin converting enzyme gene polymorphism in myocardial infarction. Journal of Taishan Medical College 21: 216-218.

Yi SD (2011). Association between I/D polymorphism in angiotensin converting enzyme and coronary artery disease. Shandong Med. J. 51: 57-58.

Yu SF, Abla A, Ibrayim A and Upur H (2009). The gene polymorphism of angiotensin-converting enzyme gene, nitric oxide synthase gene, coagulation factor VII gene and intercellular cell adhesion Molecules-1 (Icam-1) in Uighur Patients with coronary heart disease in Xinjiang. Sci. Technol. Rev 27: 76-81.

Zakrzewski-Jakubiak M, de Denus S, Dubé MP, Bélanger F, et al. (2008). Ten renin-angiotensin system-related gene polymorphisms in maximally treated Canadian Caucasian patients with heart failure. Br. J. Clin. Pharmacol. 65: $742-751$. http://dx.doi.org/10.1111/j.1365-2125.2007.03091.x

Zhang EA (2003). Association between coronary heart disease and angiotensin converting enzyme gene polymorphism. J. Pract. Med. 19: 260-261.

Zhang RZ (2004). Ace and At1r gene polymorphisms and coronary artery disease. Chin. J. Cardiovasc. Med. $19: 24-26$.

Zhang YL (2006). Relationship between polymorphism of angiotensin I converting enzyme gene insertion/deletion and ACE, PAI-I activity in patients with myocardial infarction. Chin. J. Pathophysiol. 22: 2336-2339.

Zhou L, Xi B, Wei Y, Shen W, et al. (2012). Meta-analysis of the association between the insertion/deletion polymorphism in ACE gene and coronary heart disease among the Chinese population. J. Renin Angiotensin Aldosterone Syst. 13: 296304. http://dx.doi.org/10.1177/1470320311434242

Zhu YG (2010). Association between the gene polymorphism of angiotensinogen and angiotensin converting enzyme and coronary artery disease. Chin. J. Arterioscler. 18: 405-408.

Zintzaras E, Raman G, Kitsios G and Lau J (2008). Angiotensin-converting enzyme insertion/deletion gene polymorphic variant as a marker of coronary artery disease: a meta-analysis. Arch. Intern. Med. 168: 1077-1089. http://dx.doi.org/10.1001/ archinte.168.10.1077 